\title{
TORRE DE ILUMINACIÓN Y COMUNICACIONES DE MADRID
}

\author{
(COMMUNICATIONS AND LIGHTING TOWER IN MADRID. SPAIN) \\ Salvador Pérez Arroyo \\ José Javier García Alba y Pedro Jaén Diego, Arquitectos Colaboradores
}

$504 \cdot 10$

Fecha de recepción: 22-V.92

\section{RESUMEN}

En este artículo se describe la farola de iluminación y comunicaciones de la Av. de la Victoria, en Madrid, obra enmarcada dentro del Madrid Cultural de 1992.

El objetivo de esta construcción es iluminar este nudo de confluencia vial y, al mismo tiempo, marcar un hito visual de la ciudad.

La torre-farola ilumina una superficie no menor de una hectárea y es base para la ubicación de cámaras para el control del tráfico y otros servicios.

\section{SUMMARY}

This article describes the communication and lighting tower of the Avenida de la Victoria in Madrid, a work beionging to the project of Madrid the Cultural Capital of Europe 1992.

The aim of this construction is to light this road junction and, at the same time present a visual landmark of the city.

The lantern-tower will light an area of about one hectare and will serve as a base for locating the traffic control cameras and other services.

\section{INTRODUCCIÓN}

La idea básica del proyecto era la de construir un poste de iluminación que permitiera dar luz a todo el nudo de tráfico existente junto al Arco del Triunfo, obra de Modesto López Otero y Pascual Bravo en la Ciudad Universitaria.

Se trata de un gran mueble urbano, tal y como se planteó en el concurso de remodelación del referido entorno y de la plaza de Cristo Rey. Las funciones posteriores añadidas de espacio accesible para ver la vista del entorno y la de la ciudad, o las de elemento de base para antenas de comunicación, son secundarias.

La idea fundamental estaría en un concepto de ciudad concebida con elementos de dimensiones más adecuadas para el transporte mecánico y las largas distancias. Elementos que adquieren un valor de referentes urbanos como guias que sustituyen la clá. sica idea de puertas de la ciudad.

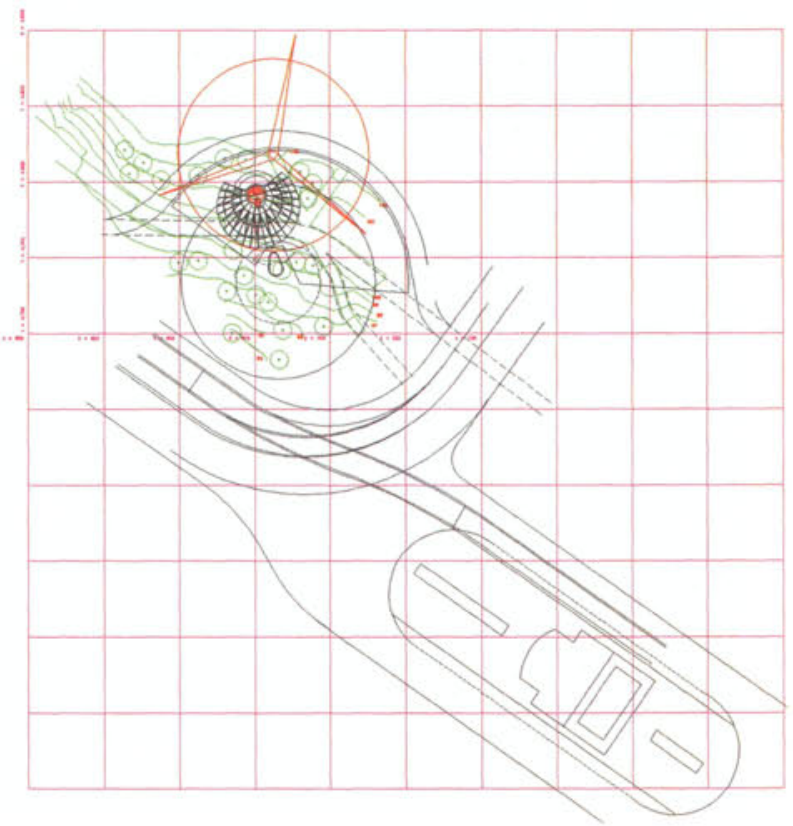

Plano de situación. 

El planteamiento formal, con una gran plataforma en voladizo en la parte superior, responde a la idea de obtener una superficie de fijación de focos hacia la zona a iluminar. Por la misma razón, la parte dirigida hacia el Museo de América no tiene más entidad que la de una pasarela de conexión de los dos lados. La necesidad de convertirlo posteriormente en un espacio accesible, por el interés que puede tener en esa parte de la ciudad como mirador, nos ha llevado al resultado que se aprecia en los planos reproducidos. La gran torre de iluminación se convierte en un faro singular, con claras referencias a la arquitectura de Van der Vlugt.

La primera idea estructural fue la de un fuste de acero, que soportaría en voladizo unas ménsulas trianguladas, las de la plataforma. Posteriormente, y desde el concurso de construcción, la empresa adjudicataria propuso la construcción del fuste con un encofra. do deslizante, es decir, en hormigón armado. La plataforma se mantiene en acero estableciéndose para ello las oportunas conexiones entre fuste y plataforma.

El fuste, de 5,90 $\mathrm{m}$ de diámetro, tiene una altura de $82,20 \mathrm{~m}$ hasta el inicio de la plataforma. En él se ubican los dos ascensores de acceso. Uno interior de servicio y otro exterior panorámico, así como la escalera principal de evacuación. La plataforma con $400 \mathrm{~m}^{2}$ está acristalada y, desde el interior, es posible observar un amplio panorama de la ciudad. Una diferencia de nivel en el suelo y una barandilla de protección interior permiten, junto al acristalamiento en techo y suelo del perímetro de la plataforma, dar una mejor sensación de comunicación con el paisaje, permitiendo un recorrido visual más amplio.

La solución estructural de la plataforma es la mencionada anteriormente. Todo el fuste y la misma plataforma se chapan en acero inoxidable mate para evitar el deslumbramiento del tráfico y para evitar una mayor presencia en la zona.

En contra de lo que se ha argumentado, su aparición en el entorno es adecuada, su perfil en la lejania de la ciudad es muy agradable, y sólo habría que aceptar como crítica una excesiva aproximación al edificio de L. Moya, debida a la imposición de no cortar un árbol para su implantación. La perspectiva del arco está libre de obstáculos y también la del edificio de Gutiérrez Soto. Su proximidad al puente de E. Torroja es coherente con una idea técnica de la ciudad. Por último, la aproximación desde el exterior a Madrid por la carretera de La Coruña es muy agradable; tres torres se unen en la misma perspectiva hacia el telón de fondo del arco de López Otero y Pascual Bravo.

\section{PROCESO CONSTRUCTIVO DE LA ESTRUCTURA DE LA PLATAFORMA SUPERIOR}

La descripción del proceso constructivo se realiza sin carácter exhaustivo, sin perjuicio del obligado cumplimiento de la totalidad de especificaciones del Pliego de Prescripciones técnicas, y del Pliego general PG-3, del M.O.P.U. en los aspectos no regulados por el anterior, asi como de las normas MV-102, MV-103, MV-104, EH-88 y demás normativa aplicable.

La ejecución de la estructura de la plataforma superior se atuvo a la siguiente secuencia de operaciones:

- Verificación especifica de cotas y dimensiones en general por los autores del Proyecto de Arquitectura.

- Verificación preliminar de las certificaciones de calidad de los materiales métalicos y demás condiciones de recepción:

- Acero tipo A52d (s. norma MV-102), homologado para los elementos del anillo de rigidez, exigiéndose en este caso certificación expresa de control ultrasónico, o șimilar, exhaustivo.

- Acero A42b (s. norma MV-102), homologado, para las cerchas y perfiles de la plataforma.

- Acero tipo 110/125, garantizado por el fabricante para las barras Dywidag de las ménsulas de apoyo M3, M4, M5, M6, M7.

- Certificación expresa de soldabilidad de los redondos de anclaje soldados a las chapas $\mathrm{H} 1, \mathrm{H} 2$, $\mathrm{H} 3, \mathrm{H} 4$ de las ménsulas de apoyo $M 1, M 2, M 8, M 9$.

- Certificación expresa de soldabilidad de los redondos de anclaje, que se soidaron a la corona superior del anillo metálico una vez completado el proceso de elevación.

- Otras calidades de materiales.

- Verificación de homologación del fabricante metálico y soldadores que intervinieron.

- Armado especial de la zona superior del fuste de hormigón, que incluye tanto la zona situada por debajo del anillo, como la zona coincidente con el mismo.

- Verificación de dimensiones y posiciones de los diversos anclajes de las ménsulas de apoyo recibidos en la estructura de hormigón. 


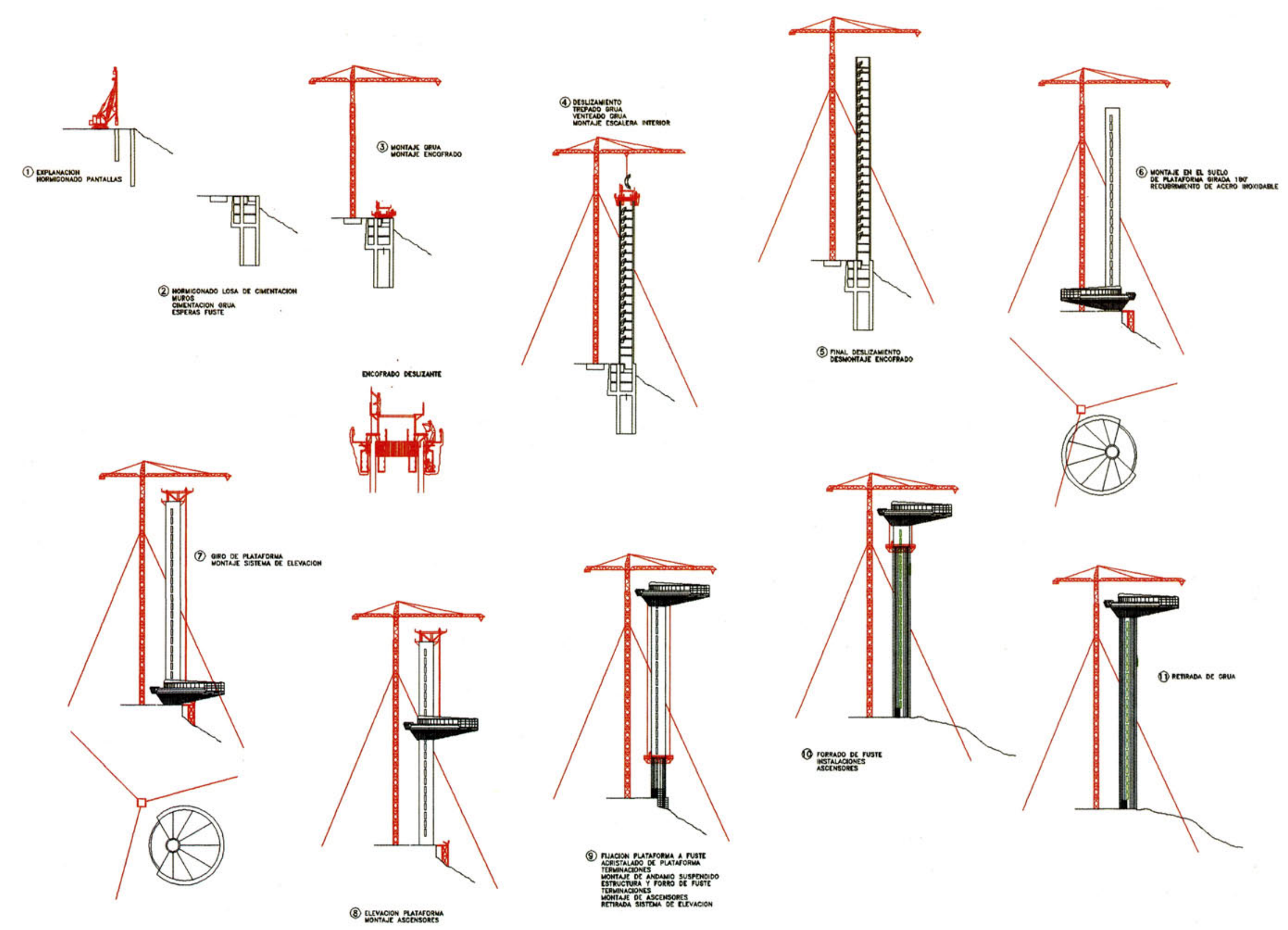




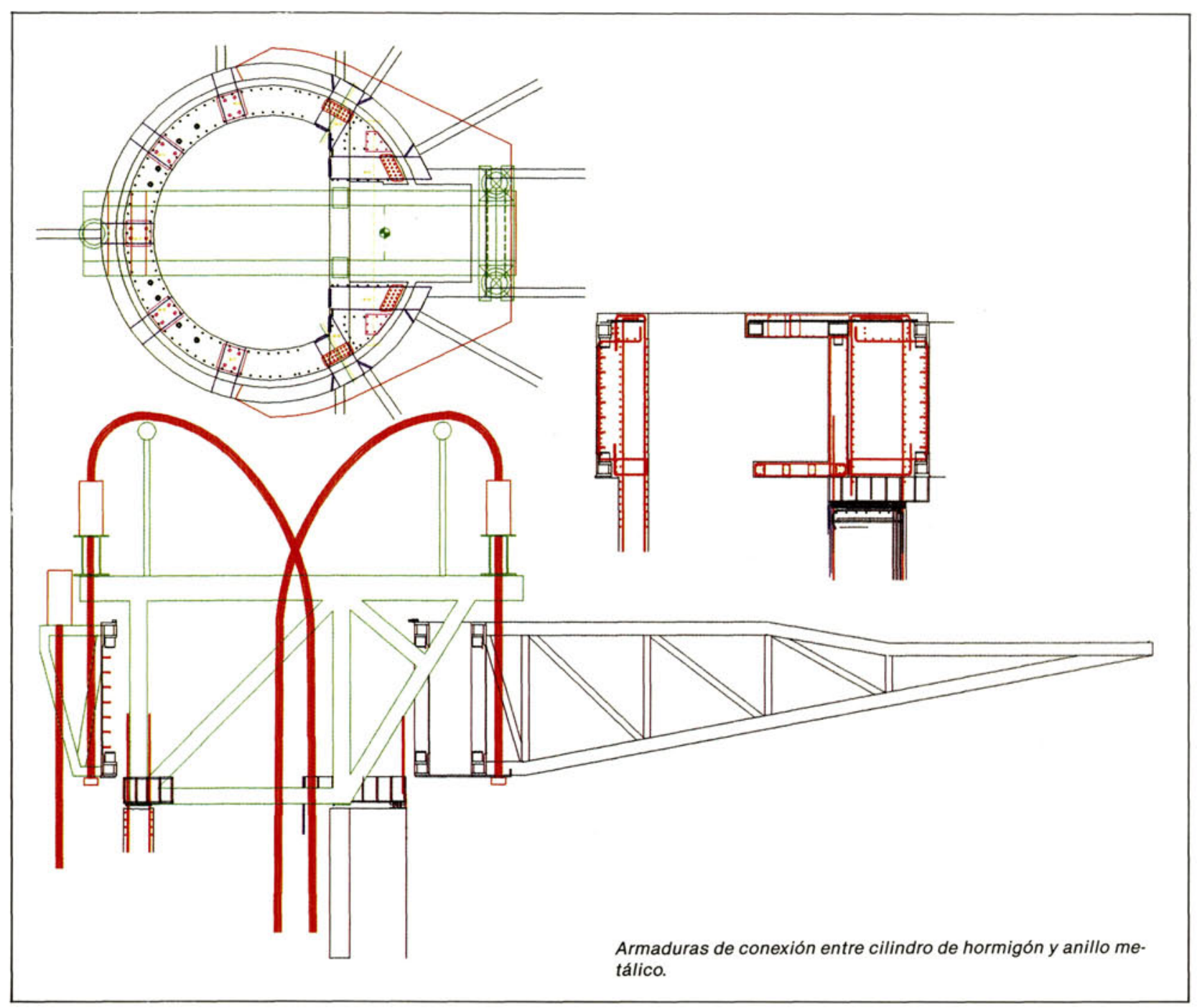

- Verificación previa a la fabricación de la estructura metálica de las dimensiones reales de obra de la estructura de hormigón armado, para su perfecta coordinación con la estructura metálica.

- Además, como medida de comprobación particular, se efectuó un premontaje de las ménsulas de apoyo del anillo de rigidez.

- En la fabricación de las cerchas principales de la plataforma se adoptaron las siguientes contraflechas (cuya validez está condicionada, lógicamente, a que el proceso constructivo descrito no sufra variaciones):

$$
\begin{aligned}
& \text { CP1: } \quad 0 \mathrm{~mm} \text {. } \\
& \text { CP2: } 45 \mathrm{~mm} \text {. } \\
& \text { CP3: } 100 \mathrm{~mm} \text {. } \\
& \text { CP4: } \quad 90 \mathrm{~mm} \text {. } \\
& \text { CP5: } \quad 55 \mathrm{~mm} \text {. }
\end{aligned}
$$

- Se montó la estructura completa de plataforma y cubierta (anillo de rigidez, cerchas principales, celosias transversales, subcorreas, arriostramientos, vigas de borde, viga balcón, soportes y viguería perimetral de la zona de núcleo, etc.), excepto lógicamente las vigas que atraviesan el núcleo.

- Antes de proseguir la ejecución, el Director de Obra verificó el carácter satisfactorio de la totalidad de controles de ejecución de la estructura metálica, que comprenden:

- Control dimensional exhaustivo.

- Control exhaustivo de posiciones relativas de elementos unidos.

- Control radiográfico de la totalidad de empalmes de chapas y perfiles.

http://informesdelaconstruccion.revistas.csic.es 


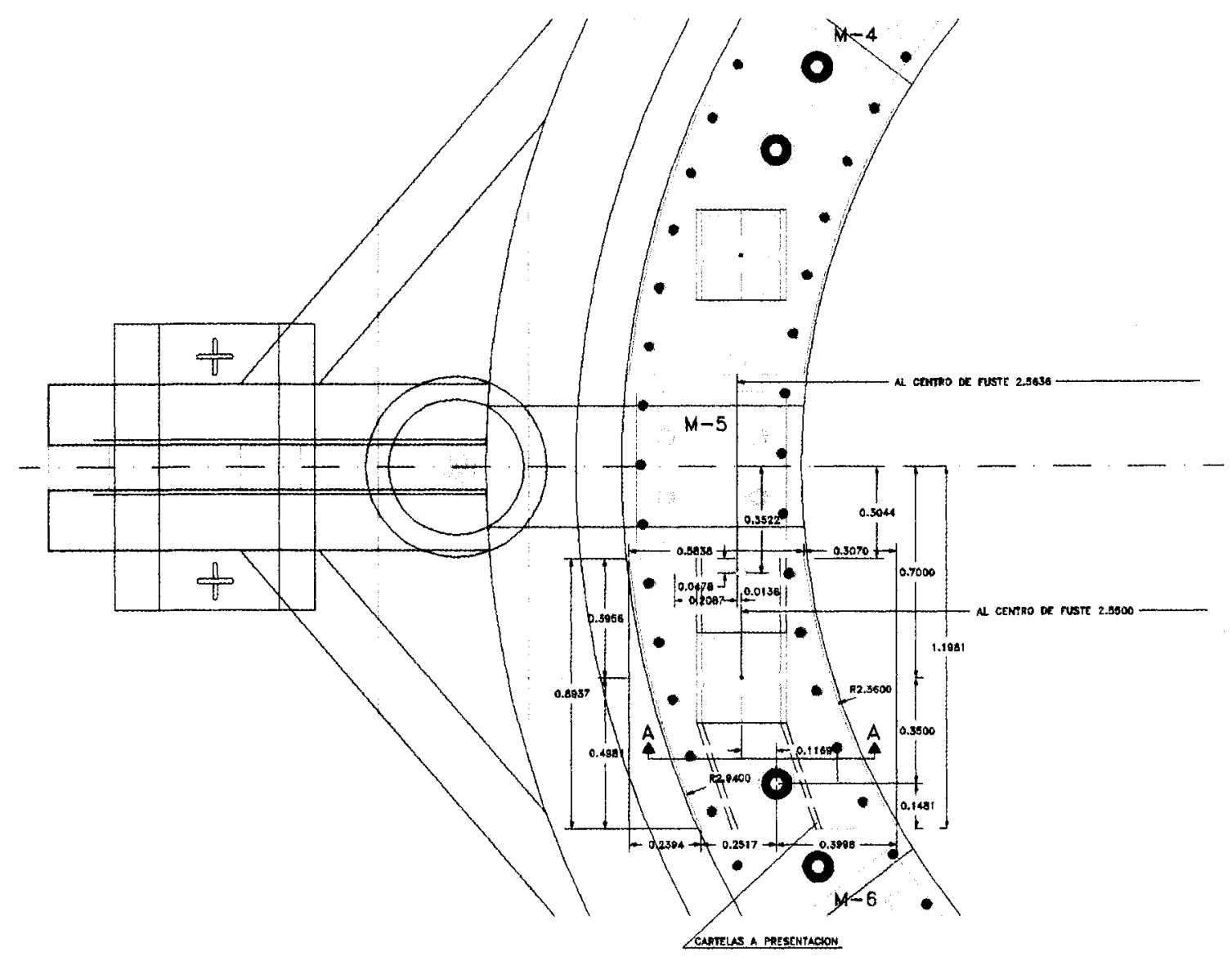

Armaduras cilindro hormigón
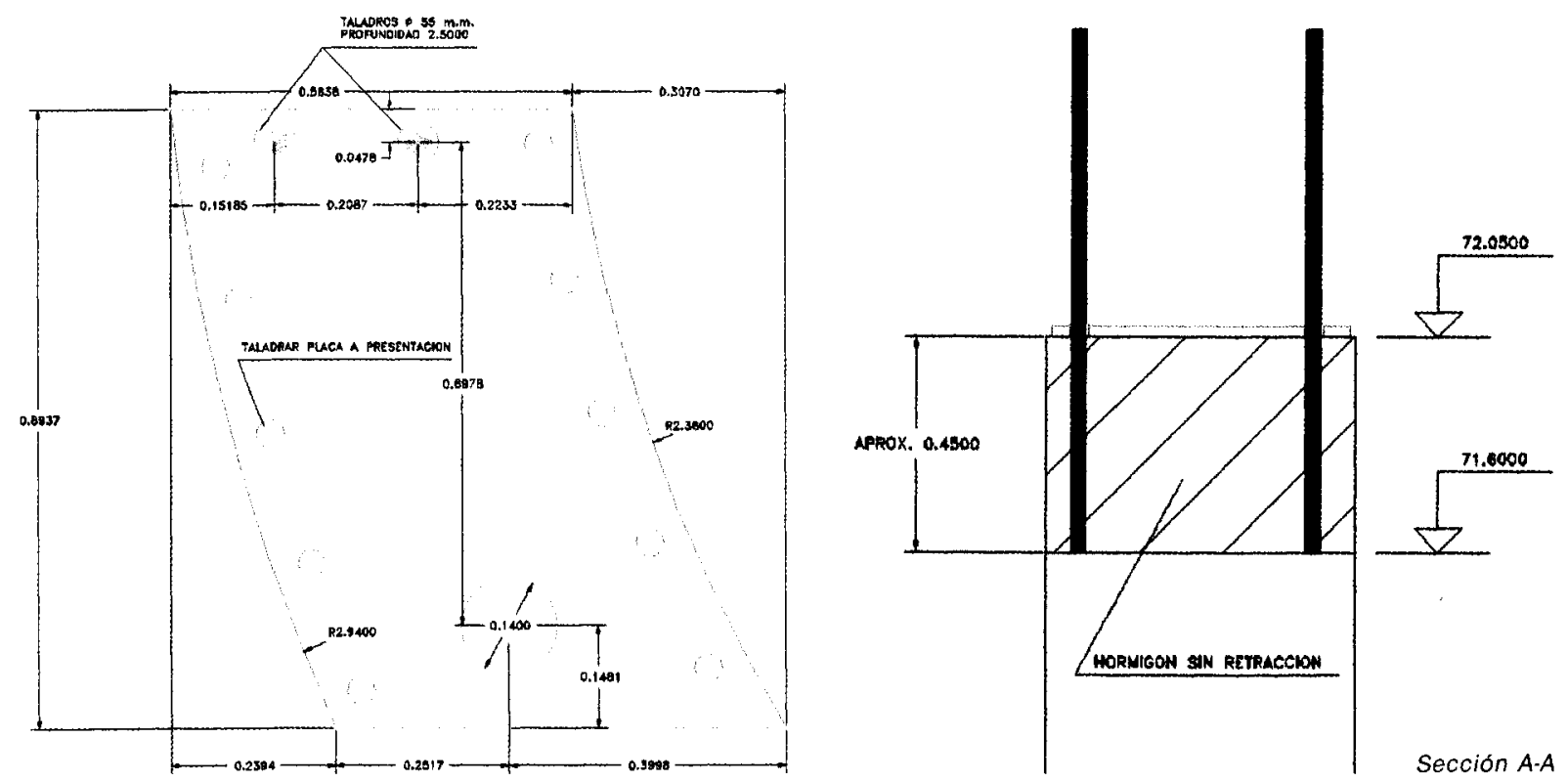

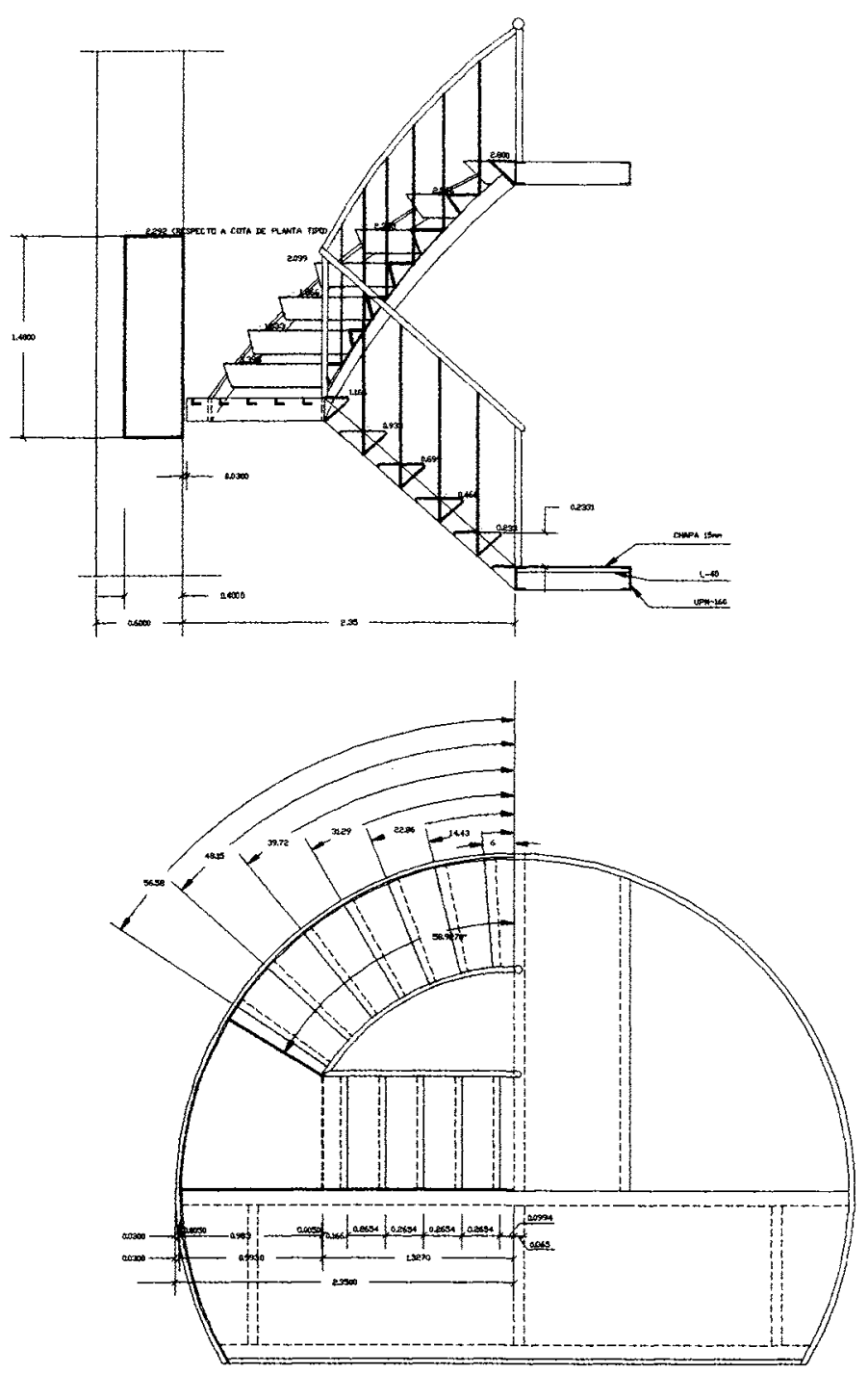

Detalle del desarrollo de escalera.

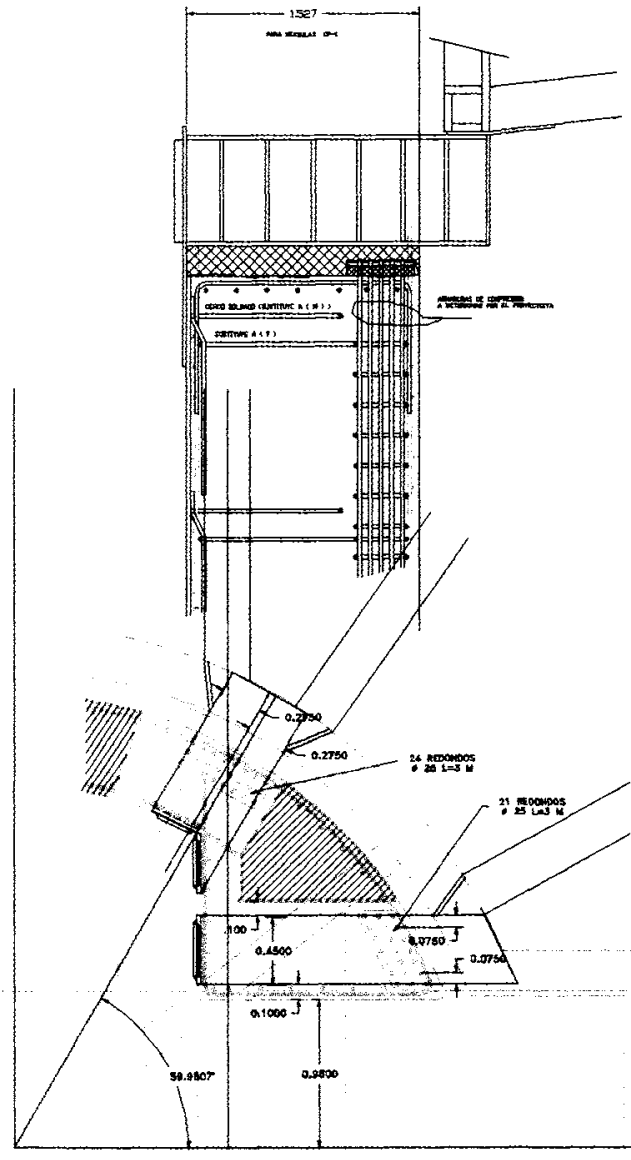

Conexiones entre ménsulas metálicas y cilindro de hormigón.

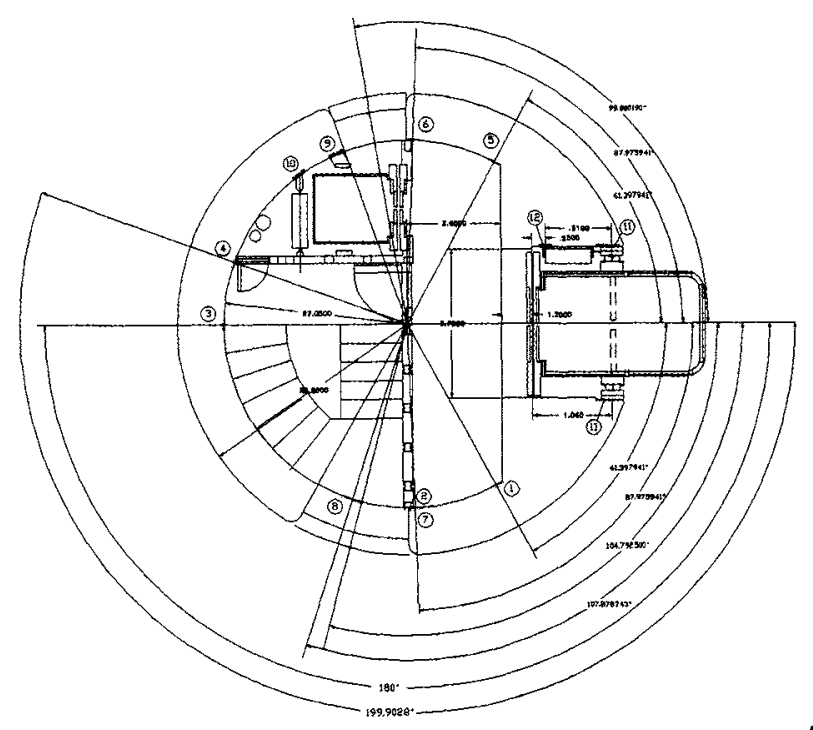

Planta general tipo. 
12

Informes de la Construcción, Vol. 44 n.o 419, mayo/junio, 1992

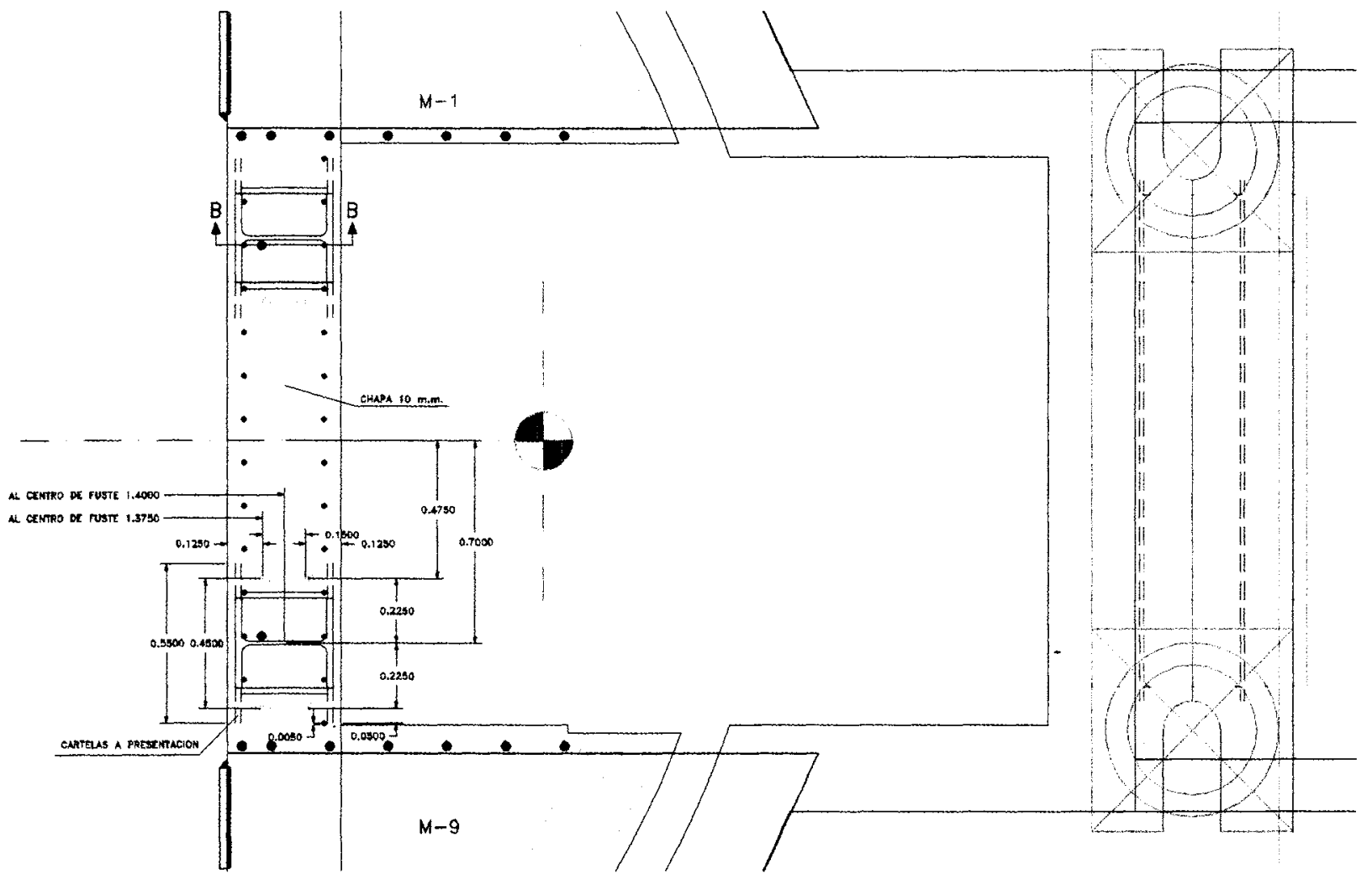

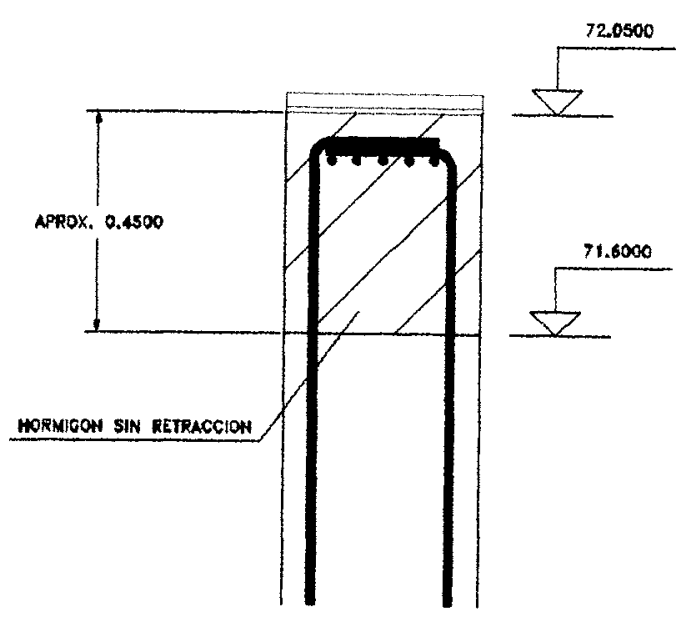

Sección $B \cdot B$

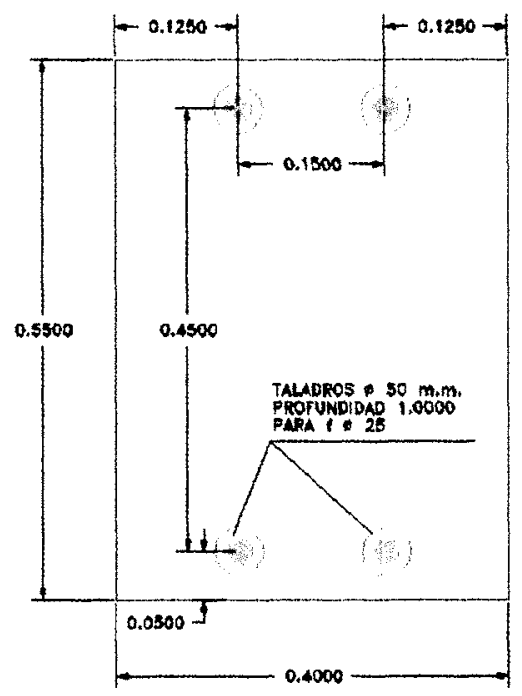

Conexión entre armaduras metálicas y de hormigón.

(C) Consejo Superior de Investigaciones Científicas

http://informesdelaconstruccion.revistas.csic.es Licencia Creative Commons 3.0 España (by-nc) 

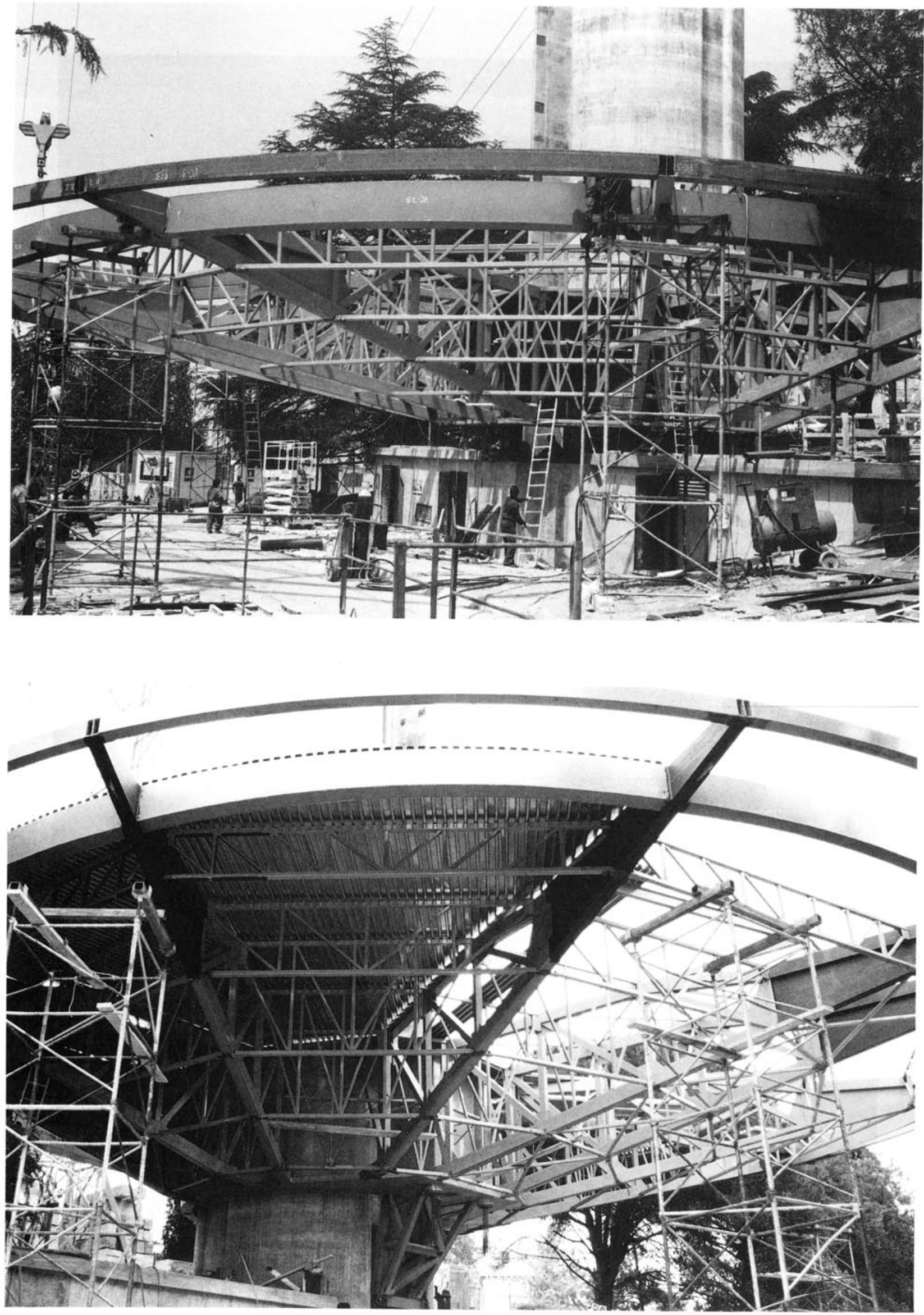


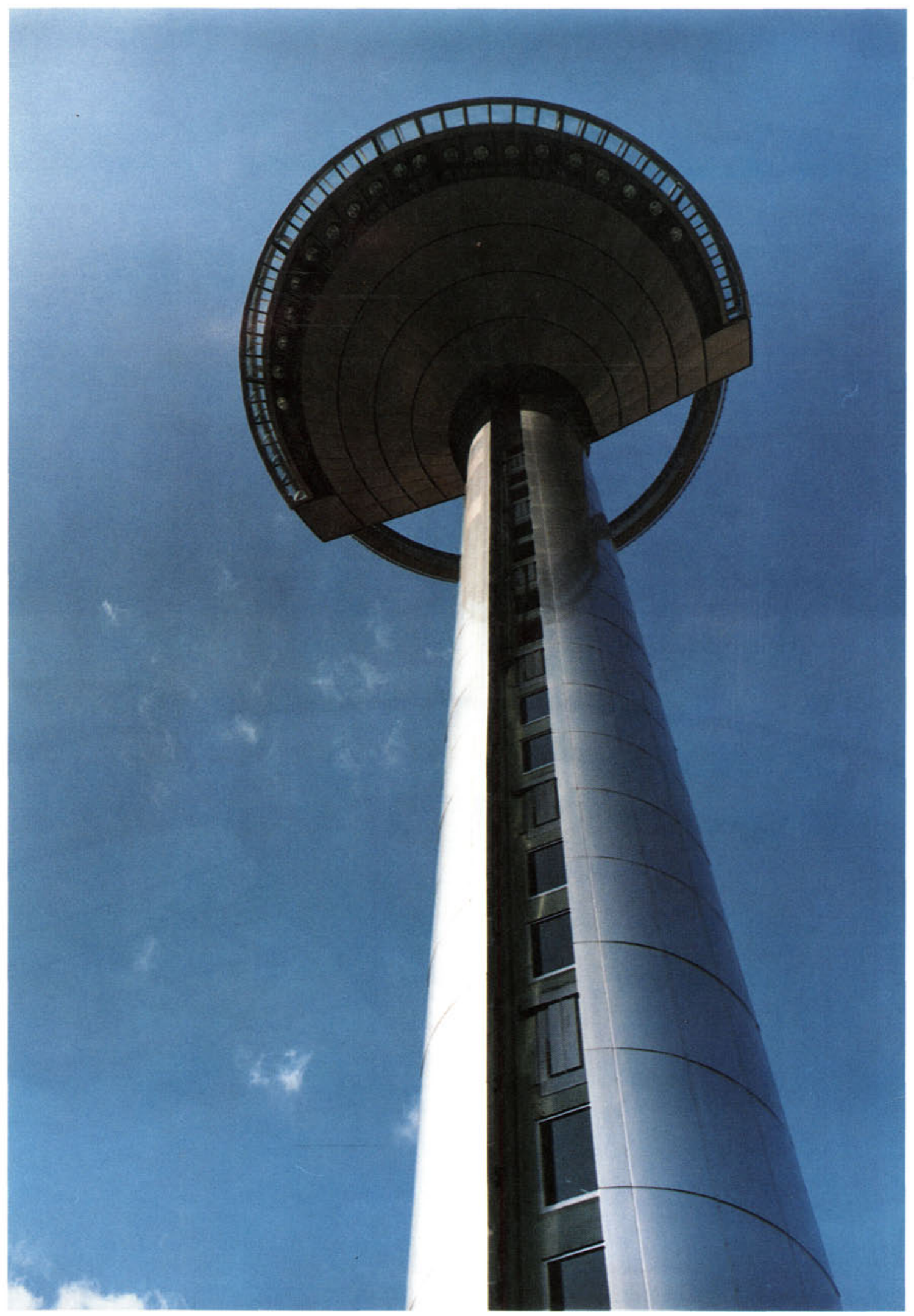

Vista peatonal del fuste. 

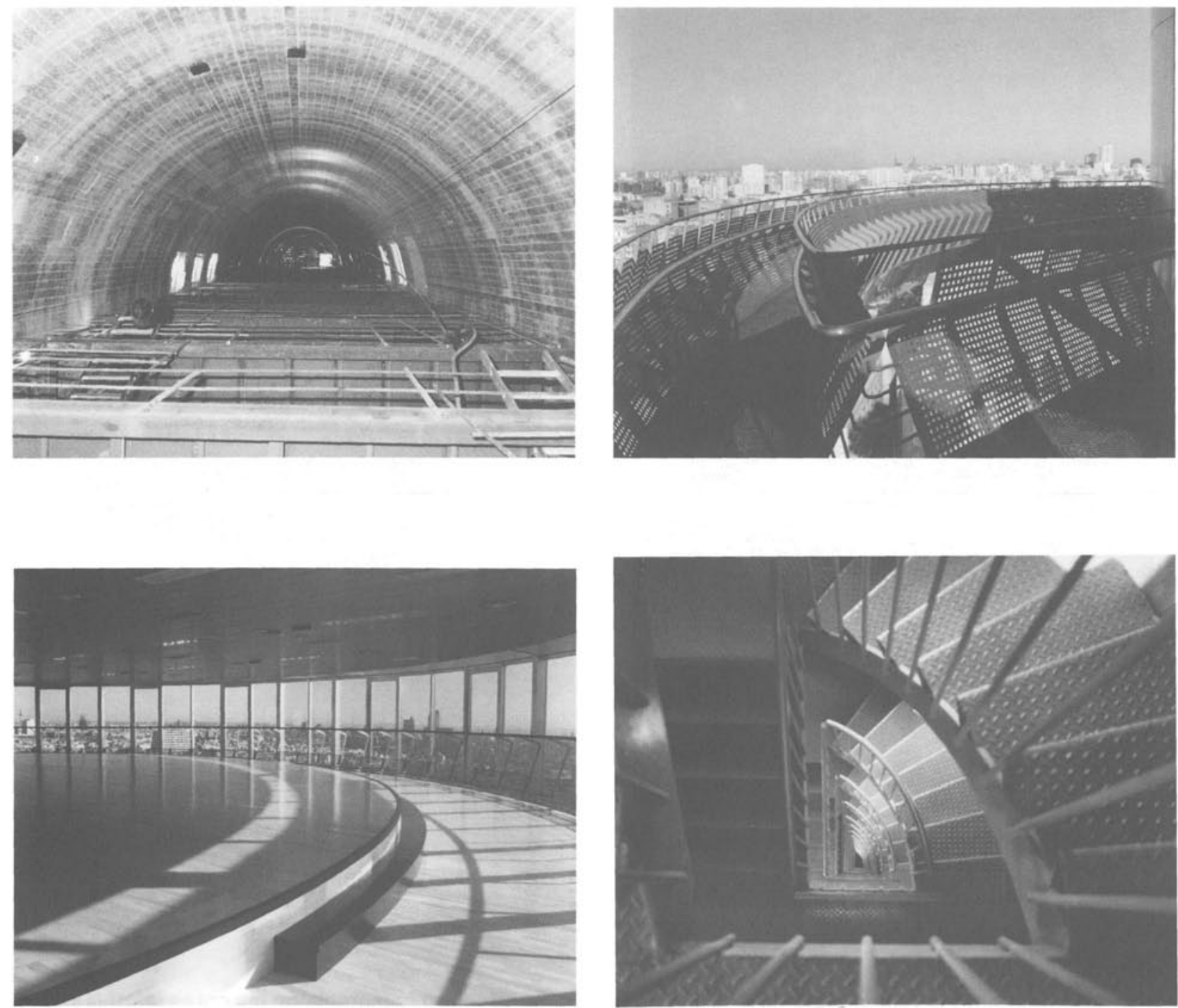

Aspectos parciales del fuste, viga balcón, salón interior y desarrollo de escalera.

- Control radiográfico de la totalidad de uniones soldadas del anillo metálico y de la viga balcón VC1.

- Control por líquidos penetrantes de las uniones de las estructuras trianguladas de plataforma y cubierta, complementándose los ensayos de control con un muestreo de radiografías de las mismas soldaduras.

- Seguidamente se colocó el lastre dispuesto en la viga balcón VC1, perfectamente amarrado. Este lastre se aplicó de forma gradual y simultánea, en ambos vanos de la viga $\mathrm{C} 1$, hasta conseguir una carga total uniformemente repartida sobre todo el desarrollo de dicha viga de $800 \mathrm{kp} / \mathrm{m}$, incluido el peso propio de la viga y demás elementos, que se controló previamente con exactitud para obtener por di(c) Consejo Superior de Investigaciones Científicas Licencia Creative Commons 3.0 España (by-nc) ferencia el peso de lastre necesario (éste se estima en $1.000 \mathrm{kp}$ por metro lineal). Se hizo una prueba de carga con una sobrecarga adicional pequeña (incremento del orden del $10 \%$ ), que luego se retiró, dejando sólo el lastre previsto. En esta prueba de carga se controlaron las deformaciones comparándolas con sus valores teóricos, que posteriormente se definieron.

- A continuación se procedió al cuelgue del contrapeso de $22 \mathrm{t}$ del punto $\mathrm{G} 3$ antes de iniciar la elevación, para lo cual se previó un foso para alojamiento del contrapeso citado.

- Antes de montarse las chapas de piso y cubrimiento debió izarse la estructura (bastaron unos centimetros) para tomar las deformaciones debidas al peso propio, evitando que éstas afectaran a los elementos constructivos mencionados.

http://informesdelaconstruccion.revistas.csic.es 


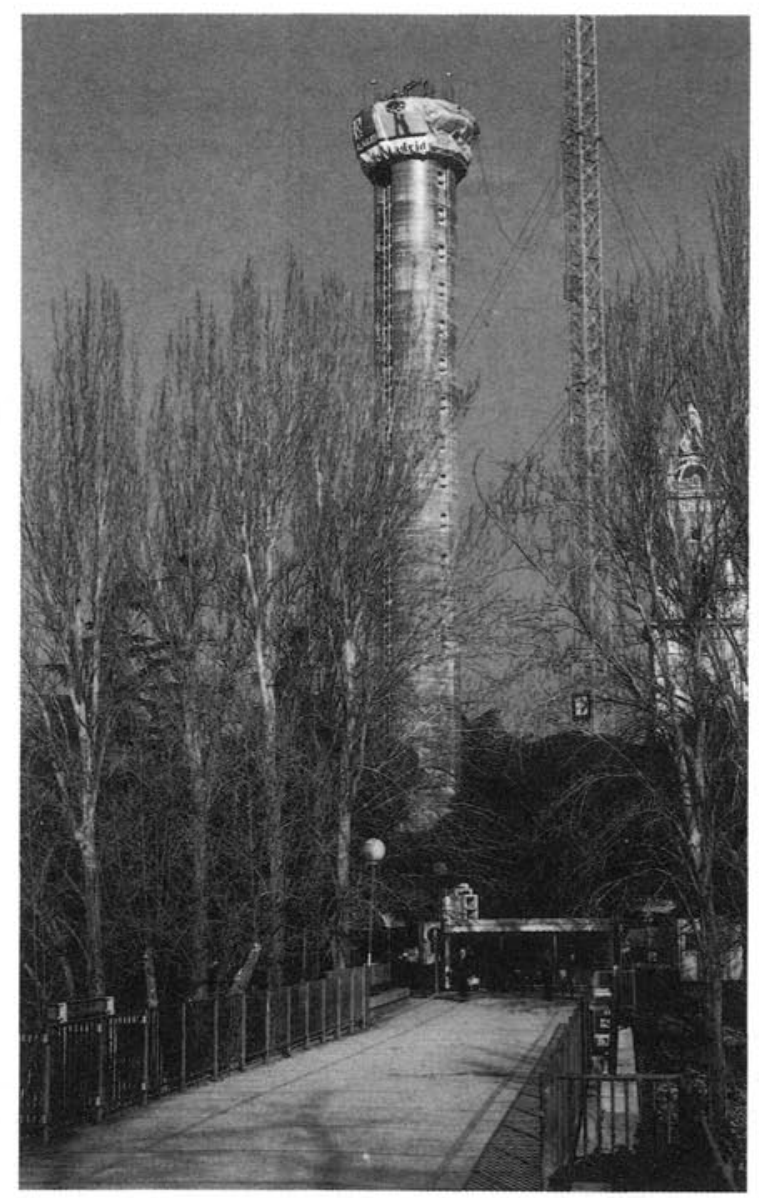

1

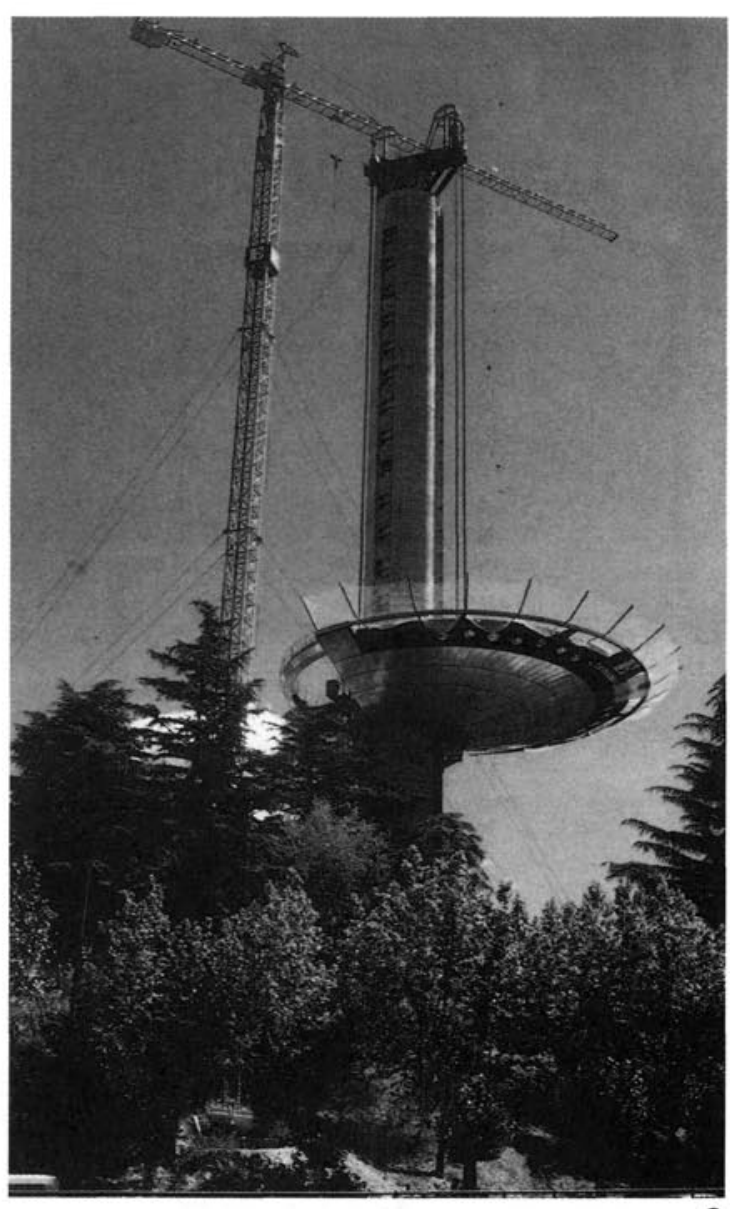

2
- Después se montó la chapa grecada del piso de la plataforma.

- A continuación se extendió la capa de hormigón ligero de piso, sólo en la zona parcial situada sobre el núcleo, comprendida entre las cerchas CP5 y la línea paralela a las mismas que pasa por los extremos del anillo metálico (puntos 11 y G1). En la zona que no se hormigonó, los anclajes de la chapa a los perfiles de la estructura no se fijaron hasta terminar las dos etapas posteriores de colocación de elementos constructivos.

- Se colocaron, seguidamente, las chapas de cubrimiento de la cubierta.

- Por último se montaron los elementos más sensibles a las deformaciones, que se estima son las rejillas y paneles de la superficie inferior de la plataforma.

- En esta fase se fijaron los anclajes de las chapas de piso y cubrimiento, que en las fases previas debían ser capaces de absorber las deformaciones que se produjeran por la propia colocación de las chapas. (c) Consejo Superior de Investigaciohes Científicas Licencia Creative Commons 3.0 España (by-nc)
- Se midieron con precisión las cotas relativas de los puntos de futuro apoyo del anillo metálico, para proceder a la exacta nivelación del mortero epoxídico de asiento en los alveolos de apoyo de la estructura de hormigón, habida cuenta de las tolerancias y deformaciones del anillo.

- Específicamente se menciona que, en la fase constructiva de elevación, no estaban colocados ni el resto de hormigón ligero, ni elementos de piso, barandillas, falso techo, instalaciones, cristaleras, etcétera.

- Los tirantes de elevación actuaron sobre tres puntos: los dos puntos simétricos $\mathrm{G} 1$ y el tercer punto G2, estimándose reacciones características equivalentes máximas (sin mayorar) del orden de $100 \mathrm{t}$ en cada uno de los tres puntos citados. Se dispuso de tirantes en los dos puntos simétricos G4, para controlar posibles cabeceos de la plataforma, asi como de guias verticales apropiadas para evitar desplazamientos y rotaciones.

- Una vez completada la elevación de la estructura se fijaron, inmediatamente, las ménsulas de apoyo del 


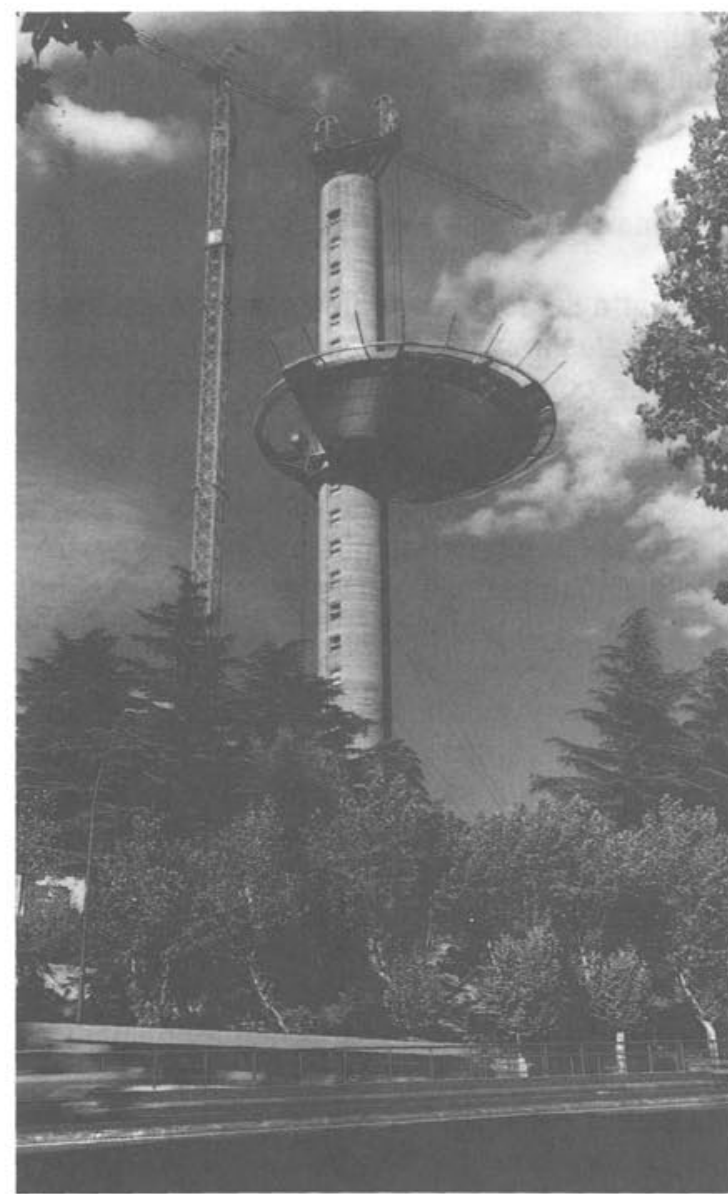

3

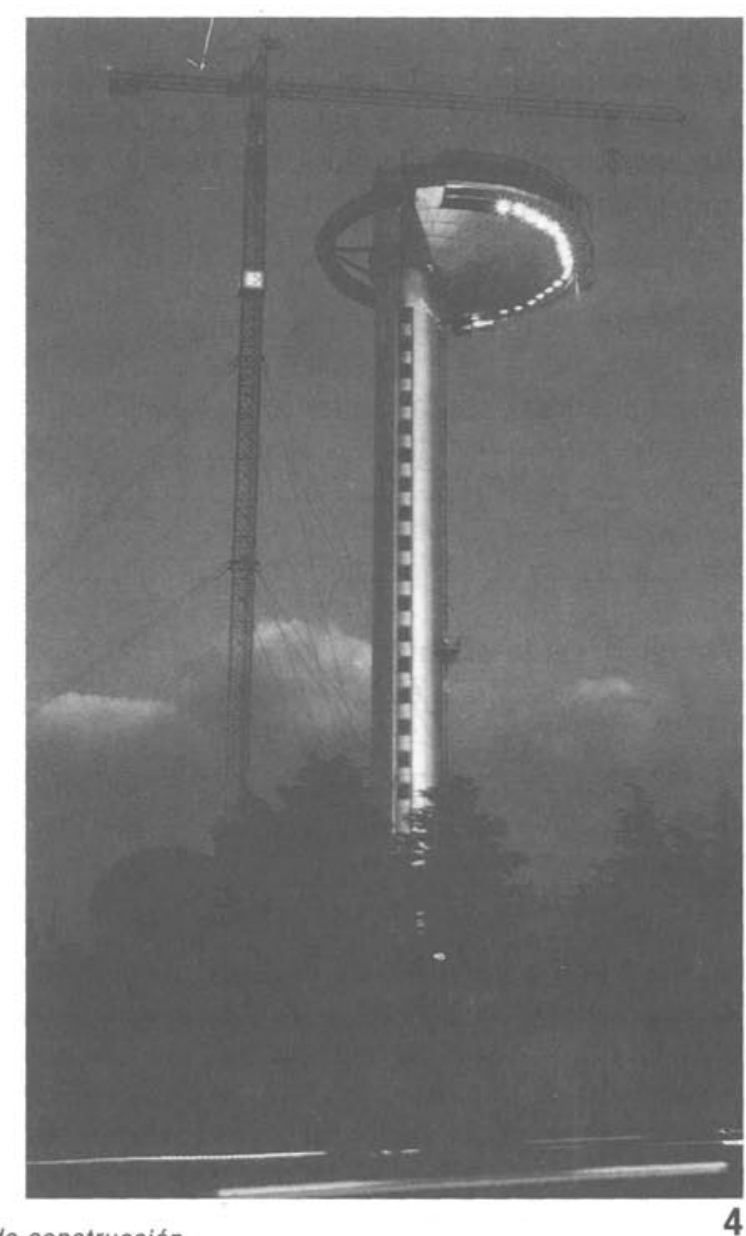

4 anillo de rigidez. En particular, se efectuaron controles radiográficos exhaustivos de la totalidad de las soldaduras efectuadas en esta fase.

- Una vez unidas las ménsulas de apoyo al anillo métalico y a la estructura de hormigón, antes de retirar los gatos y tirantes de elevación, y antes de la colocación de ninguna carga adicional sobre la plataforma, debia materializarse integramente la unión al fuste de hormigón, es decir, el ferrallado y hormigonado del tramo final del mismo conectado al aniIlo metálico (incluidos los diafragmas vertical y horizontal), lógicamente previa soldadura de las piezas diametrales de atado y de los redondos superiores de anclaje al fuste de hormigón, soldados a la cabeza superior del anillo métalico.

- Los gatos y tirantes de elevación no se retiraron has. ta después de la consecución de $3 / 4$ de la resistencia característica del último volumen de hormigón colocado en el anillo de rigidez, lo cual se controló mediante los oportunos ensayos informativos.

- A continuación se retiró el contrapeso y el lastre de la viga VC1, procediendo de manera gradual y simul(C) Consejo Superior de Investigaciones Científicas Licencia Creative Commons 3.0 España (by-nc) tánea en los dos vanos de dicha viga VC1, es decir, se evitó que en ningún momento pudieran quedar ambos vanos con cargas desiguales.

- Para empezar la colocación de cargas adicionales de la plataforma debió obtenerse el $100 \%$ de la resistencia característica exigida en el Proyecto.

La presente descripción del proceso constructivo debió someterse a la aprobación del Director de Obra, quien recabó toda la información precisa del constructor y empresa responsable del proceso de elevación.

\section{CARACTERÍSTICAS PRINCIPALES}

La torre está formada por un fuste de hormigón, cimentado mediante pantallas in situ y una plataforma de coronación acristalada visitable de construcción metálica, a la que se accede por un ascensor adosado al exterior del fuste. La plataforma, de planta circular, de 27,90 m de diámetro exterior, está situada desplazada respecto al eje vertical de la torre, con una excentricidad de $4 \mathrm{~m}$.

http://informesdelaconstruccion.revistas.csic.es 
El fuste se construyó mediante hormigonado continuo con encofrado deslizante.

La estructura metálica de la plataforma se montó en el suelo, izándola colgada por medio de gatos hidráulicos hasta su posición en lo alto de la torre y hormigonando a continuación su unión con el fuste de hormigón.

Las principales dimensiones de la farola son:

- Altura libre total sobre cimientos $83,00 \mathrm{~m}$

- Diámetro exterior del fuste $5,90 \mathrm{~m}$

- Espesor del fuste $0,60 \mathrm{~m}$

- Diámetro máximo de la plataforma ....... 27,90 m

- Profundidad de la cimentación $18,00 \mathrm{~m}$

Sobre el techo de la plataforma se ha instalado una antena para comunicaciones del Ayuntamiento de Madrid.

\section{El fuste}

El fuste tiene una altura total de $75 \mathrm{~m}$, de sección circular hueca constante en toda su altura, de $5,90 \mathrm{~m}$ de diámetro exterior y $60 \mathrm{~cm}$ de espesor de pared. El anillo está cortado en uno de los extremos de su eje de simetría, donde se ha dispuesto un cajeado vertical de 1,90 $\mathrm{m}$ de ancho para alojar el ascensor panorámico principal de acceso a la plataforma. La continuidad entre los dos labios de la caja del ascensor se restablece mediante un muro interior, en el que se dejan los huecos de las puertas del ascensor.

La posición de la plataforma de coronación, con una excentricidad de $4,00 \mathrm{~m}$ respecto al eje vertical de la torre, ha llevado a una solución de fuste de hormigón con un pretensado también excéntrico, que contrapese la plataforma y constituido por 6 tendones de pretensado, distribuidos en el extremo diametralmente opuesto al hueco del ascensor.

El pretensado vertical del fuste consiste en 6 tendones con su extremo superior en la parte más aita del fuste, al nivel de la plataforma visitable y su extremo inferior en la losa de encepado de las pantallas de cimentación. El trazado de los tendones sigue las generatrices del fuste con una curva de salida en su extremo inferior. El pretensado se aplica al extremo superior, siendo pasivos los anclajes del extremo inferior, no accesibles a los gatos de pretensado.

El espacio interior del fuste se reparte entre la escalera, de planta curva con un total de 26 plantas, y la caja para un segundo ascensor, interior, de servicio y emergencia, además de los huecos para las distintas conducciones de las instalaciones de la torre.
En la base del fuste se dispone, entre la losa de encepado de las pantallas de cimentación y la sección del fuste circular antes descrita, un plinto de sección octogonal para los fosos de los dos ascensores de la torre.

\section{Plataforma de coronación}

La parte alta del fuste se refuerza para resistir los esfuerzos locales transmitidos por la estructura de la plataforma de coronación durante las operaciones de izado y en servicio.

Las cargas de las cerchas de la plataforma se recogen en un anillo de rigidez, que apoya en la parte alta del fuste mediante unas ménsulas metálicas al finalizar el izado de la plataforma.

Una vez apoyada la plataforma en las ménsulas se hormigonaron los últimos $3,60 \mathrm{~m}$ del fuste, con un espesor de 1,05 $\mathrm{m}$ para solidarizar el anillo de rigidez al resto del fuste ya construido. En este tramo la sección del fuste es completamente cerrada, rodeando el hueco del ascensor exterior una vez que éste ha alcanza. do ya el nivel de la plataforma.

La magnitud de los esfuerzos transmitidos por la plataforma obliga a un considerable aumento de la armadura en esta zona del fuste.

La plataforma de coronación es de planta circular de $27,90 \mathrm{~m}$ de diámetro exterior. Parte de su superficie se deja sin piso, resultando una superficie visitable de 400 metros cuadrados.

La estructura, tanto de la planta de la plataforma co mo de su cubierta, está formada por cerchas metálicas de longitud y canto variables. Las diez cerchas del piso arrancan del anillo de rigidez antes mencionado, que rodea completamente al fuste para transmitirle las cargas de plataforma.

\section{Efecto sísmico}

En la Norma Sismorresistente P.D.S.-1 (1974) Madrid tiene un grado de intensidad (5) según la tabla 3.1., correspondiente a zona sísmica primera, de sismicidad baja, por lo que no es necesario efectuar cálculos sísmicos.

\section{Peso propio y cargas muertas}

Para el fuste se considera su peso propio y el de elementos anejos (escaleras y revestimiento).

Para la plataforma se considera el peso de los elemen. tos que la componen. 


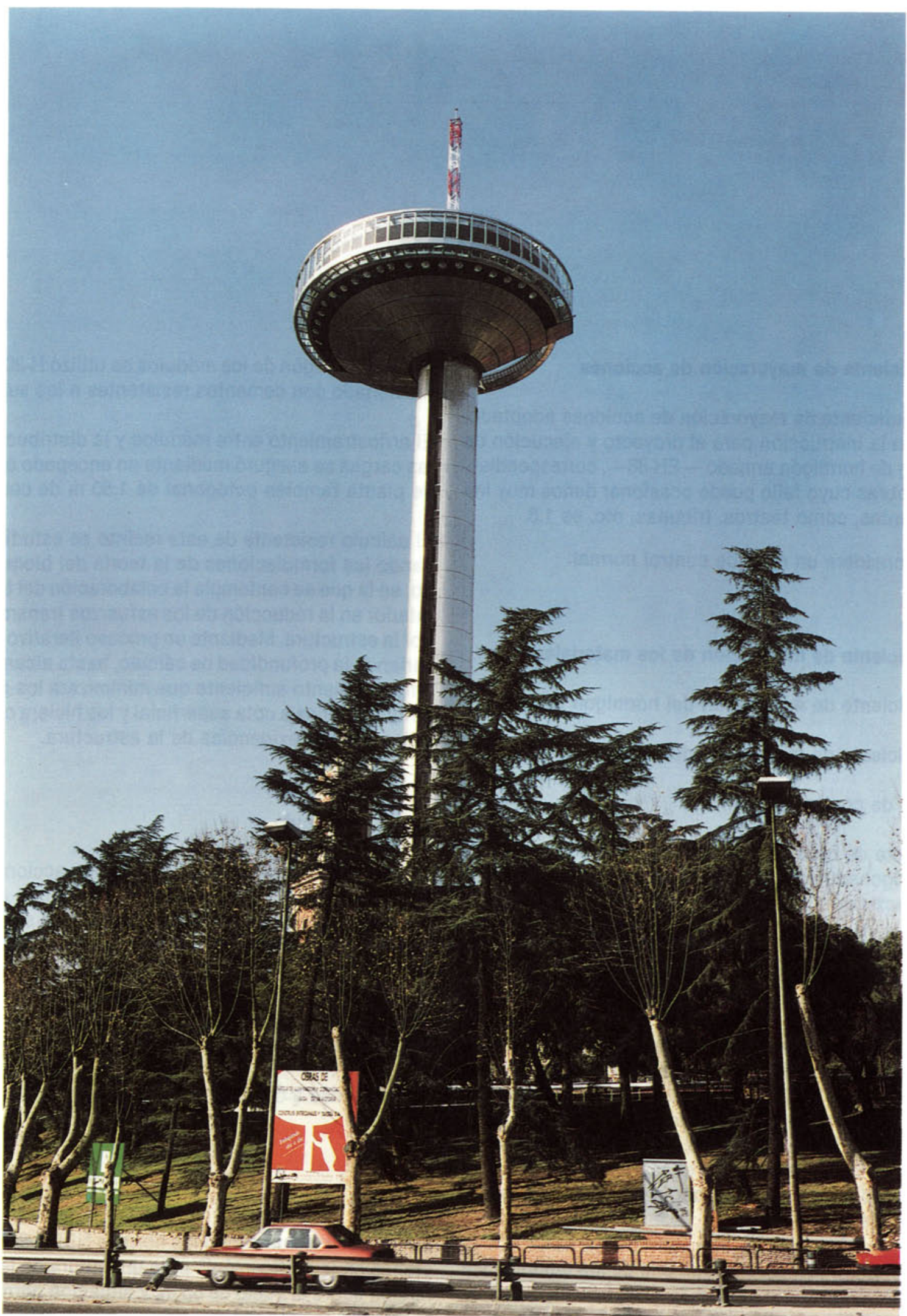

Vista desde el Arco de la Victoria. 


\section{Coeficiente de mayoración de acciones}

El coeficiente de mayoración de acciones adoptado, según la Instrucción para el proyecto y ejecución de obras de hormigón armado -EH-88-, correspondiente a obras cuyo fallo puede ocasionar daños muy importantes, como teatros, tribunas, etc. es 1.8 .

Se considera un nivel de control normal.

\section{Coeficiente de minoración de los materiales}

Coeficiente de minoración del hormigon fc $=1,5$.

Coeficiente de minoración del acero fs $=1,15$.

Nivel de control normal.

El fuste de hormigón se considera como un soporte hormigonado en vertical, por lo que la resistencia de proyecto se minora además un $10 \%$.

\section{Cimentación}

La cimentación de la torre se realizó mediante murospantallas distribuidos en planta, formando un octógono regular de 3,127 m de lado. La excavación se ejecutó mediante cuchara guiada en módulos de $2,60 \mathrm{~m}$ de profundidad, al amparo de lodos bentoníticos. A esta profundidad las pantallas quedaron suficientemente empotradas en los suelos tosquizos de la facie terciaria de Madrid.

La armadura vertical de cada uno de los módulos está formada por redondos $\varnothing 25 \mathrm{cada} 0,20 \mathrm{~m}$, distribuidos en ambas caras. La armadura horizontal está compuesta por cercos $\varnothing 12$ cada $0,20 \mathrm{~m}$. Para la rigidización de la jaula resultante se dispusieron redondos $\varnothing 16$ en toda su profundidad.
Para el hormigón de los módulos se utilizó H-200 confeccionado con cementos resistentes a los sulfatos.

El arriostramiento entre módulos y la distribución de las cargas se aseguró mediante un encepado común, de planta también octogonal de $1,50 \mathrm{~m}$ de canto.

El cálculo resistente de este recinto se estudió aplicando las formulaciones de la teoría del bloque rígido, en la que se contempla la colaboración del terreno interior en la reducción de los esfuerzos transmitidos por la estructura. Mediante un proceso iterativo se fue variando la profundidad de cálculo, hasta alcanzar un empotramiento suficiente que minimizara los giros y deformaciones a cota superficial y los hiciera compatibles con las exigencias de la estructura.

\section{Bases de cálculo}

La torre se dimensiona para resistir las acciones del viento en las distintas direcciones, junto con los esfuerzos producidos por el peso propio y las sobrecargas actuando sobre la plataforma de coronación. Asimismo se ha estudiado la deformabilidad de la torre y las oscilaciones producidas por el viento sobre la misma, que la podrían hacer incómoda para los visitantes de la plataforma.

Las acciones a considerar en el proyecto de la torre fueron:

\section{Viento}

Se aplica el viento según las normas NBE-AE/88 "ACciones en la edificación": para una altura de la coronación sobre el suelo de $85 \mathrm{~m}$, y situación normal; de la tabla 5.1 resulta una velocidad de viento de $144 \mathrm{~km} / \mathrm{h}$ y presión de $100 \mathrm{~kg} / \mathrm{m}^{2}$. A esta presión dinámica se aplican los coeficientes eólico y de esbeltez correspondientes a cada elemento de la estructura. 


\section{Sobrecargas de uso}

Plataforma superior visitable:

- Zona pública $250 \mathrm{~kg} / \mathrm{m}^{2}$

- Zona de terrazas $250 \mathrm{~kg} / \mathrm{m}^{2}$

- Balcón acristalado $200 \mathrm{~kg} / \mathrm{ml}\left(^{*}\right)$

- Escaleras y descansillos $400 \mathrm{~kg} / \mathrm{m}^{2}$

(") según el artículo 3.5 de la norma NBE-AE/88

\section{Sobrecargas de nieve}

Según la tabla 4.1 de la norma citada se toma una sobrecarga de $80 \mathrm{~kg} / \mathrm{m}^{2}$.

\section{Ascensor panorámico}

Tiene una capacidad de carga de $1.000 \mathrm{~kg}$ dando acceso a 13 personas, con recorrido de $73 \mathrm{~m}$ y una velocidad de $1,60 \mathrm{~m}$ por segundo. El sistema de regulación electrónica de la velocidad hace posible una nivelación automática en las paradas. El camarín dispone de una luna de seguridad doble de $6+6 \mathrm{~mm}$ y está equipado con un moderno sistema de aire acondicionado. Su funcionamiento se controla por un equipo de protección y mando basado en la tecnología de los microprocesadores que garantiza un servicio óptimo diario.

\section{FICHA TECNICA}

Localización: Avda. de la Victoria, Madrid.

Promotor: Excmo. Ayuntamiento de Madrid.

Redacción de Proyectos: sept.-diciembre, 1990

Ejecución de las Obras: 1991.

Proyecto y Dirección de Obra: Salvador Pérez Arroyo, Arquitecto

Colaboradores: José Javier García Alba, Arquitecto

Pedro Jaén Diego, Arquitecto

Yolanda Rios Vanejo, Arquitecta

Eva Hurtado Torán, Arquitecta

Fernando Río Durán, Arquitecto

Julián Rodríguez Henche, Arquitecto

Andrés Pérez Romeral, Aparejador

Andrés Canelas Pastor, Delineante
Ingeniería: Manuel Thomé Guesala

Juan Antonio Domínguez Montero

José Espinosa González

M. Jesús Izquierdo Martínez Jesús Ortiz Herrero

Coordinadores de Obra: José Luis Díaz de Rojas

Manuel Lloréns Alcon

Javier Urquijo Grijalba

Taller de Estructura Metálica: Gonzalo Rodriguez González Antonio Ortiz Pérez

Constructora: ENTRECANALES $Y$ TAVORA

Ascensor Panorámico: GIESA SCHINDLER, S. A. 